Este trabajo ha obtenido un Accésit del Premio Estudios Financieros 2016 en la modalidad de Educación y Nuevas Tecnologías. El jurado ha estado compuesto por: don Antonio Bautista Garcia-Vera, don Luis Alberto Guijarro Rojo, doña Ana Hidalgo Tena, doña Blanca Lozano Cutanda y don José Eugenio Martínez Falero. (Los trabajos se presentan con seudónimo y la selección se efectúa garantizando el anonimato de los autores)

Mercedes Segarra Ciprés ${ }^{1}$, Reyes Grangel Seguer ${ }^{2}$, Óscar Belmonte Fernández ${ }^{3}$ y Sergio Aguado González ${ }^{4}$

\title{
¿Cómo potenciar el emprendimiento y la innovación mediante el desarrollo de proyectos de base tecnológica en el contexto docente universitario?
}

\section{Sumario}

1. Introducción

2. Bases teóricas de la experiencia docente

3. Contexto de la experiencia

4. Metodología de trabajo

5. Resultados obtenidos

6. Valoración de la experiencia

7. Conclusiones

8. Bibliografía

Anexo

\section{Extracto:}

El emprendimiento, junto a la innovación, son dos de los valores más demandados por las empresas en la actualidad y por ello las competencias asociadas son potenciadas en los grados con un claro enfoque hacia el emprendimiento. El objetivo es que el alumnado que salga de sus aulas sea capaz de emprender, y no solo en el sentido de crear una empresa, sino que tenga la capacidad de innovar en todas aquellas tareas que su desempeño profesional requiera. Sin embargo, a pesar de la clara necesidad de potenciar el emprendimiento, existen pocos ejemplos prácticos de cómo enseñar esta competencia. En este artículo presentamos una experiencia docente basada en el marco teórico proporcionado por el Modelo de la Triple Hélice, según el cual las sinergias en el emprendimiento se multiplican cuando confluyen tres ejes en la tarea de emprender: institucional, universitario y empresarial. Su objetivo ha sido acompañar al alumnado desde la idea de negocio hasta la creación de una empresa de base tecnológica, como una forma de potenciar su capacidad emprendedora y de innovación. Para llevarla a cabo se ha creado un grupo de trabajo multidisciplinar en el cual, a nivel del eje universitario, se han coordinado asignaturas de diferentes ámbitos de conocimiento: ingeniería, ciencias sociales y humanidades.

Palabras clave: emprendimiento, innovación, Modelo Triple Hélice, competencias emprendedoras, empresas de base tecnológica, coordinación docente.

\footnotetext{
M. Segarra Ciprés, profesora contratada doctora del Departamento de Administración de Empresas y Marketing de la Facultad de Ciencias Jurídicas y Económicas de la Universitat Jaume I.

${ }^{2}$ R. Grangel Seguer, profesora contratada doctora del Departamento de Lenguajes y Sistemas Informáticos de la Escuela Superior de Tecnología y Ciencias Experimentales de la Universitat Jaume I.

3 Ó. Belmonte Fernández, profesor titular de universidad del Departamento de Lenguajes y Sistemas Informáticos de la Escuela Superior de Tecnología y Ciencias Experimentales de la Universitat Jaume I.

${ }^{4}$ S. Aguado González, CTO en Soluciones Cuatroochenta, SL.
} 


\section{How to encourage entrepreneurship and innovation through the development of technology-based projects in the context of university teaching?}

\section{Abstract:}

Entrepreneurship and innovation are two of the values demanded by firms today, and therefore the associated skills are enhanced in grades with a clear focus on entrepreneurship. The goal is that students who leave their classrooms were able to undertake and not only in the sense of creating a firm, but also to have the ability to innovate in any tasks that require professional performance. However, despite the clear need to promote entrepreneurship, there are few practical examples of how to teach this competence. In this paper, we present an educational experience based on the theoretical framework provided by the Triple Helix Model, according to which synergies in entrepreneurship are multiplied when are joined the three axes in the task of undertaking: institutional, university and business. Its goal has been to support students from the business idea to the creation of a technologybased company, as a way to enhance their entrepreneurial and innovative capacity. To carry it out has created a multidisciplinary working group in which at university axis level courses of different knowledge domain have been coordinated: engineering, social sciences and humanities.

Keywords: entrepreneurship, innovation, Triple Helix Model, entrepreneurial skills, technology-based firms, educational coordination.

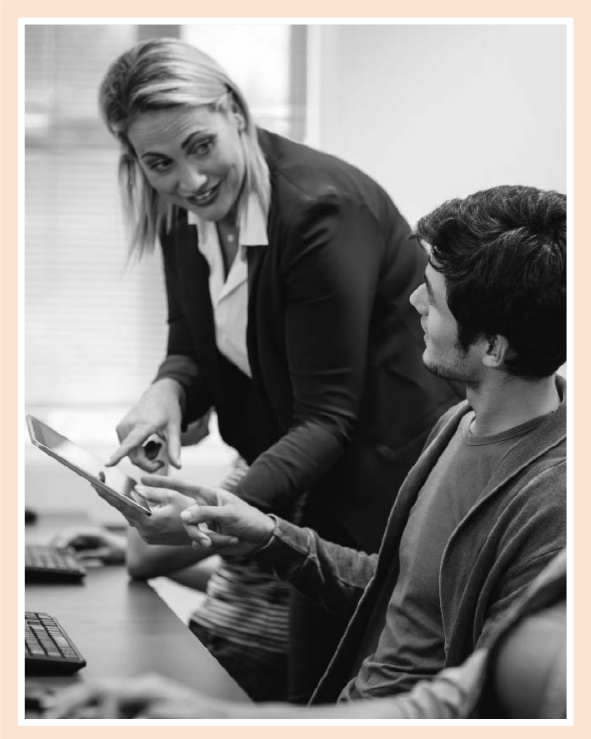

\section{INTRODUCCIÓN}

En el escenario actual de la educación superior en España, las competencias en materia de emprendimiento adquieren relevancia como ejes sobre los que articular el conocimiento y las habilidades adquiridas en la etapa universitaria. En el Libro blanco de la iniciativa emprendedora en España (2011) se pone de manifiesto la necesidad de promover el espíritu emprendedor de un modo eficaz y se articulan las directrices para tratar de crear un entorno favorable. Una de las medidas contempladas es la formación de competencias emprendedoras para el fomento de una actitud favorable y para desarrollar la sensibilización hacia el autoempleo. Para conseguir que la transferencia de conocimiento desde el ámbito universitario se transforme en el nacimiento de empresas resulta crucial la colaboración de la universidad con el tejido empresarial, así como la labor de las instituciones como ejes vertebradores de esta colaboración. En esta línea, el Modelo de la Triple Hélice (Etzkowitz y Leydesdorff, 2000) recoge la colaboración entre tres ejes como son la universidad, la industria y las instituciones, como base para fomentar la innovación y el crecimiento económico de las regiones. 
En el presente artículo aplicamos las enseñanzas de este modelo a una experiencia docente en el ámbito de la educación en nuevas tecnologías, con la finalidad de integrar el aprendizaje de las competencias emprendedoras e innovadoras en un ambiente académico. El resultado es una experiencia docente que se ha llevado a cabo a modo de proyecto piloto, en la cual han participado tres asignaturas del grado de Ingeniería Informática de la Universitat Jaume I de Castellón de la Plana. En esta experiencia generamos un contexto de emprendimiento dentro de la formación académica universitaria para que los alumnos puedan desarrollar sus proyectos de creación de empresas de base tecnológica, facilitando que las empresas del sector de las tecnologías de la información y la comunicación (TIC) y los alumnos de otras especialidades colaboren en el desarrollo y en la evaluación de los proyectos.

La experiencia docente ha incluido tres asignaturas del grado:

- Iniciativa Empresarial. En la cual el alumnado ha trabajado la generación de ideas para la creación de empresas de base tecnológica y ha elaborado un plan de negocio.

- Métodos Ágiles. En la cual se ha seguido la metodología Scrum Manager (Scrum Manager, 2016) para la planificación y la ejecución del proyecto software obtenido de dicho plan de negocio.

- Taller de Ingeniería del Software. En la cual el alumnado ha implementado el proyecto software con tecnologías web de última generación.

El objetivo de esta experiencia docente no ha sido solo la coordinación docente entre tres asignaturas, sino que ha ido más allá, puesto que, aplicando el Modelo de la Triple Hélice, ha permitido implicar en el contexto universitario a los otros dos ejes del modelo: el institucional, mediante la valoración y el acompañamiento de los proyectos por parte de diversas instituciones y organismos dedicados al emprendimiento, y el empresarial, con la participación de empresas reales del sector en la aportación y valoración de ideas, así como en el seguimiento y en la posible financiación de los proyectos.

\section{En el escenario actual de la educación superior en España, las competencias en materia de emprendimiento adquieren relevancia como ejes sobre los que articular el conocimiento y las habilidades adquiridas en la etapa universitaria}

La finalidad última es que el alumnado adquiera, mediante una experiencia práctica real y potenciada por el Modelo de la Triple Hélice, las competencias de emprendimiento e innovación que el actual mercado laboral demanda. Finalmente, se han analizado los resultados de la experiencia piloto con el fin de mejorarla en el próximo curso e implicar a un mayor número de actores que puedan crear una cultura emprendedora en el grado, en particular, y en la universidad, en general. Para ello, se ha realizado una encuesta con la finalidad de valorar cómo la experiencia ha modificado las percepciones de los estudiantes sobre el significado de emprender e innovar y cómo ha mejorado sus competencias emprendedoras.

En el siguiente apartado se detallan las bases teóricas sobre las que se ha basado la experiencia docente presentada en el artículo. En los apartados 3 y 4 , se presentan el contexto de la experiencia y la metodología de trabajo que se ha seguido. El apartado 5 muestra los proyectos que han surgido de la experiencia docente, así como las colaboraciones llevadas a cabo siguiendo la metodología explicada. Finalmente, en el apartado 6 se analiza la valoración que el alumnado ha hecho de la experiencia y en el apartado 7 se detallan las conclusiones del trabajo. 


\section{BASES TEÓRICAS DE LA EXPERIENCIA DOCENTE}

\subsection{El Modelo de la Triple Hélice}

El Modelo de la Triple Hélice (Etzkowitz y Leydesdorff, 2000) se fundamenta en el análisis de las relaciones e interacciones mutuas entre tres elementos, como son la universidad, la industria y el Gobierno, y que configura la base del modelo económico de una sociedad basada en el conocimiento y en sus estrategias de innovación. Sobre estas relaciones se plantea un esquema facilitador de la planificación de las actuaciones públicas y de la toma de decisiones de las instituciones en materia de enseñanza universitaria, investigación científica y tecnológica, y de sectores industriales, con el objetivo de impulsar la innovación y favorecer el crecimiento económico. Este modelo tiene su origen en EE. UU., donde existe una amplia tradición de colaboración entre los ámbitos académicos e industriales, entre la universidad y las agencias gubernamentales, y entre el Gobierno y las industrias. El modelo propone que la innovación surge de las interacciones y de las comunicaciones mutuas entre los agentes de la hélice (véase figura 1). Cada agente aporta un valor a la hélice, que se multiplica con las interacciones entre los agentes: la universidad (primera aspa) representa el principal agente de generación y difusión de conocimiento; las empresas e industrias (segunda aspa), como agentes de generación y explotación de nuevas oportunidades de negocio; y el Estado (tercera aspa), como agente regulador de las relaciones entre los agentes.

El Modelo de la Triple Hélice (...) se fundamenta en el análisis de las relaciones e interacciones mutuas entre tres elementos, como son la universidad, la industria y el Gobierno, y que configura la base del modelo económico de una sociedad basada en el conocimiento y en sus estrategias de innovación

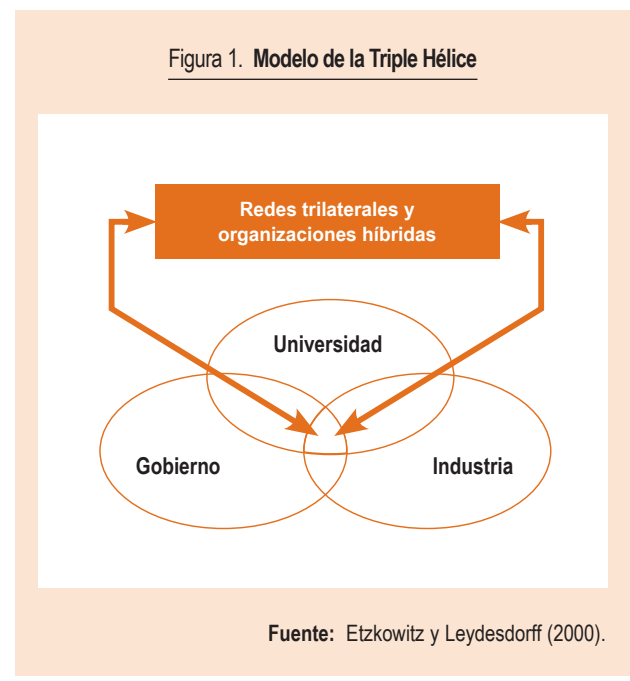

Estos tres agentes, trabajando de forma conjunta y siguiendo un modelo en espiral, se acaban convirtiendo en socios estratégicos y haciendo que cada uno tome el papel del otro (Leydesdorff, Dolfsma y Van der Panne, 2006). La universidad asume el papel de la industria cuando crea nuevas empresas para capitalizar el conocimiento de sus investigaciones. Las empresas forman a sus empleados y comparten conocimiento mediante la creación de joint ventures. El estado desarrolla el rol de capitalista público y regula las relaciones entre los agentes mediante la legislación y el establecimiento de instrumentos e incentivos fiscales. Esta cooperación trilateral deriva en una confluencia de sinergias que conforman el eje para impulsar los sistemas regionales de innovación (Etzkowitz y Ranga, 2010). El éxito de esta triple alianza regional depende de la capacidad de los agentes para establecer alianzas sólidas y viables. Además, del solapamiento de las tres esferas, emergen organizaciones híbridas.

La evolución del Modelo de la Triple Hélice ha situado a las universidades como el eje vertebrador del modelo y les ha conferido el rol de universidades emprendedoras. 


\subsection{Las universidades emprendedoras}

La formación y la investigación son las funciones que tradicionalmente ha desempeñado la universidad. Sin embargo, Etzkowitz y Leydesdorff (2000), en su modelo, ya anunciaban su tercera función, «la universidad emprendedora», impulsora del emprendimiento tecnológico, clave en los procesos de transferencia de tecnología y base para la incubación de empresas en sus instalaciones. En la actualidad, el papel de las universidades en el funcionamiento de un sistema local de innovación es estratégico, así como su influencia en el desarrollo económico y social local, mediante innovaciones basadas en el conocimiento. Es con esta nueva misión donde surge la responsabilidad de generar soluciones innovadoras en función del conocimiento y con el fin de resolver problemas regionales mediante el fortalecimiento de los vínculos con las empresas (Clark, 1998). Por su parte, las universidades encuentran en la colaboración con las empresas la oportunidad para acceder a nuevas fuentes de financiación, así como la posibilidad de mejorar el estado de la técnica y obtener las bases para orientar la investigación básica. El resultado final tiene una doble consecuencia para la universidad; por un lado, refuerza su función social, al ofrecer servicios públicos que contribuyen al bienestar social, y, por otro, se reduce la brecha entre la investigación universitaria y las necesidades reales de la sociedad. En este contexto surge una figura que aúna el conocimiento y la innovación, el «científico emprendedor» (Viale y Etzkowitz, 2005), y se produce la transferencia de tecnología mediante la creación de spin-off o empresas creadas con el fin de explotar una parte de la propiedad intelectual generada en una institución académica (Shane, 2004). Estas iniciativas provienen generalmente de los grupos de investigación y están lideradas por profesores en su rol de investigadores. En cambio, no suele ser habitual que este tipo de iniciativas emprendedoras se inicien en el ámbito docente y que los estudiantes sean los promotores del proyecto.

La experiencia docente que presentamos en este artículo recoge este tipo de iniciativas emprendedoras de base tecnológica, que nacen como parte del trabajo de las asignaturas, en las que los estudiantes desarrollan sus competencias emprendedoras poniendo en marcha un proyecto propio, acompañados por el profesorado y con el apoyo de instituciones y empre-

\section{La experiencia docente que \\ presentamos en este artículo recoge \\ este tipo de iniciativas emprendedoras \\ de base tecnológica, que nacen como \\ parte del trabajo de las asignaturas, \\ en las que los estudiantes \\ desarrollan sus competencias \\ emprendedoras poniendo en marcha \\ un proyecto propio, acompañados \\ por el profesorado y con el apoyo de \\ instituciones y empresas del sector \\ de las TIC}

sas del sector de las TIC. Por lo tanto, esta estructura de relaciones reproduce la dinámica del Modelo de la Triple Hélice en un ámbito distinto al inicialmente propuesto por sus creadores, como es el ámbito docente. En los apartados 4 y 5 se detalla, respectivamente, el contexto de la experiencia docente, así como la metodología de trabajo seguida, explicando la forma en que los agentes que conforman la Triple Hélice han colaborado con el alumnado para potenciar sus competencias emprendedoras a la hora de poner en marcha sus propios proyectos de base tecnológica.

\subsection{Las competencias emprendedoras: ini- ciativa y espíritu emprendedor}

Con la aplicación de los principios del Espacio Europeo de Educación Superior (EEES) (Bologna Process, 2016), el concepto de "competencia» ha sustituido al de «objetivos» como un fin más amplio en el cual no solo tienen cabida los conocimientos que se pretenden enseñar, sino también las habilidades y actitudes, así como el grado en que ese aprendizaje se consigue. En el proyecto Tuning (Wagenaar, 2003), las competencias se definen como la combinación de conocimiento, aptitudes y destrezas, y el nivel o grado de suficiencia con que una persona es capaz de desempeñarlas, diferenciándose entre «específicas», o propias de cada área temática, y «genéricas», las cuales pertenecen al ámbito personal. 


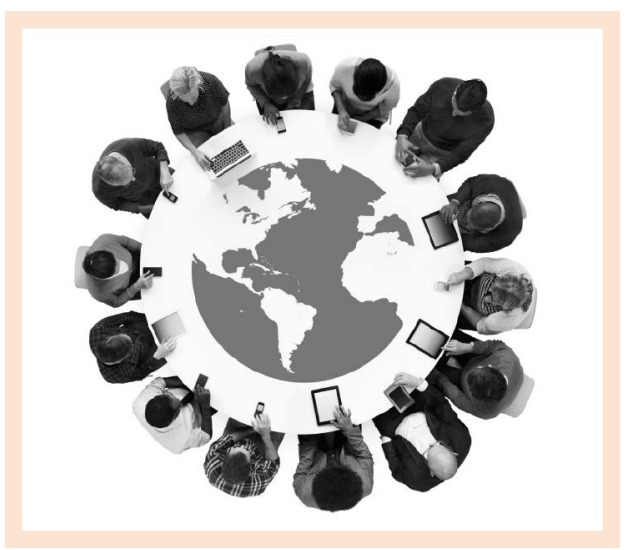

La competencia en iniciativa y espíritu emprendedor se cataloga como competencia de carácter transversal, lo que significa que es común a todos los perfiles profesionales o disciplinas y, por tanto, no es específica para un área profesional concreta. La naturaleza transversal, dinámica e integral de esta competencia requiere que el proceso de enseñanza-aprendizaje competencial se aborde desde distintas áreas de conocimiento $\mathrm{y}$, por tanto, el desarrollo de esta competencia requiere la coordinación entre asignaturas alineadas en torno a la misma (Miró y Jaume, 2010), lo que recoge la esencia de la experiencia docente presentada en este artículo.

Según la Recomendación del Parlamento Europeo y del Consejo de 18 de diciembre de 2006 sobre las competencias clave para el aprendizaje permanente, la iniciativa y el espíritu de empresa se define como «(...) la habilidad de la persona para transformar las ideas en actos. Está relacionada con la creatividad, la innovación y la asunción de riesgos, así como con la habilidad para planificar y gestionar proyectos con el fin de alcanzar objetivos» (Comisión Europea, 2006). La implementación de esta competencia responde a la exigencia por parte del EEES del papel dinamizador de la universidad. Dicha exigencia se concreta a través de la utilización de metodologías activas, como el aprendizaje basado en proyectos (ABP), y el desarrollo de competencias, como el trabajo en equipo, la autonomía, la iniciativa, la creatividad y la asunción de riesgos, que forman parte fundamental de las memorias de verificación de los títulos oficiales del nuevo espacio de educación en España (Batista et al., 2015).
A la hora de abordar los contenidos y la metodología de la iniciativa emprendedora en la enseñanza universitaria, los expertos señalan que estos pueden variar en función de si los estudiantes proceden de disciplinas empresariales o si proceden de otro tipo de disciplinas. En general, sostienen que los estudiantes de ingeniería y ciencias preferirán un enfoque más práctico y que necesitarán nociones básicas de economía, marketing y técnicas de gestión. Por otra parte, este tipo de estudiantes son competentes en el ámbito técnico y, generalmente, tienen ideas sólidas en materia de productos. Sin embargo, este enfoque les lleva a cometer un error habitual, que consiste en desarrollar primero el producto y solo después estudiar las posibilidades en el mercado (Comisión Europea, 2008). En cuanto a la metodología, el citado informe de la Comisión Europea señala las características que la enseñanza de las competencias emprendedoras debería tener para lograr el éxito. Entre otras, destacan las siguientes:

- El aprendizaje de las capacidades emprendedoras requiere un método de enseñanza centrado en el estudiante, con unos resultados de aprendizaje claramente especificados.

- El uso de métodos de enseñanza basados en la experiencia es crucial para el desarrollo de conocimientos y de las capacidades emprendedoras.

- La enseñanza debería estar basada en un enfoque interdisciplinar, cuyo objetivo último fuera mezclar a estudiantes procedentes de diferentes facultades y distintos ámbitos de estudio para que cooperaran en el desarrollo de actividades y proyectos conjuntos.

(...) la experiencia que explicamos en
estas líneas pretende valorar en qué
medida una metodología docente
que reproduce la dinámica de las
relaciones del Modelo de la Triple
Hélice puede modificar la percepción
del alumnado sobre su intención de
emprender

(...) la experiencia que explicamos en estas líneas pretende valorar en qué medida una metodología docente que reproduce la dinámica de las relaciones del Modelo de la Triple Hélice puede modificar la percepción emprender 
La literatura académica en materia de emprendimiento aborda el estudio sobre los comportamientos emprendedores de los individuos desde distintos enfoques. Uno de los pioneros es el enfoque de los rasgos de personalidad (McClelland et al., 1953), que parte del análisis de las características psicológicas de los individuos como base para diferenciar a los emprendedores de otros grupos de individuos. Otros enfoques han puesto el acento en las características sociodemográficas de los individuos y en los factores del entorno como aspectos clave que explican las condiciones emprendedoras de los individuos (Arenius y Minniti, 2005). Sin embargo, estos enfoques han demostrado una limitada capacidad predictiva, por lo que en los últimos años los investigadores se han centrado en desarrollar una perspectiva más dinámica, basada en las actitudes y en los aspectos cognitivos de los individuos. En esta línea, las actitudes pueden condicionar las intenciones de los individuos a seguir un comportamiento emprendedor y, concretamente, la intención emprendedora, entendida como el propósito de crear una empresa o la intención de ser autoempleado, se presenta como un antecedente clave del comportamiento emprendedor, frente a otros aspectos como los derivados de la personalidad o los factores de entorno (Krueger y Casrud, 1993).

En el ámbito de la investigación educativa, la educación en emprendimiento ha recibido una atención es- pecial en los últimos años, especialmente los estudios que analizan el impacto de los programas formativos sobre la orientación emprendedora de los estudiantes (Pittaway y Cope, 2007). En esta línea, Peterman y Kennedy (2003) examinan los efectos de la participación en un programa de emprendimiento sobre las percepciones de los estudiantes respecto a la conveniencia y a la viabilidad al comenzar un negocio. Concretamente, estos autores analizan tres aspectos:

- La intención o deseabilidad percibida, que se refiere a la percepción de obtener beneficios deseables derivados de emprender.

- La viabilidad percibida, que recoge la percepción sobre la facilidad o dificultad para llevar a cabo la acción de emprender.

- La conveniencia percibida, que recoge la percepción sobre la accesibilidad a los medios y recursos necesarios para emprender.

Siguiendo a estos autores, la experiencia docente que explicamos en estas líneas pretende valorar en qué medida una metodología docente que reproduce la dinámica de las relaciones del Modelo de la Triple Hélice puede modificar la percepción del alumnado sobre su intención de emprender. En los siguientes apartados se presenta el contexto docente de la experiencia y se describe con detalle la metodología de trabajo que ha guiado dicha experiencia.

\section{Figura 2. Asignaturas coordinadas en la experiencia docente}
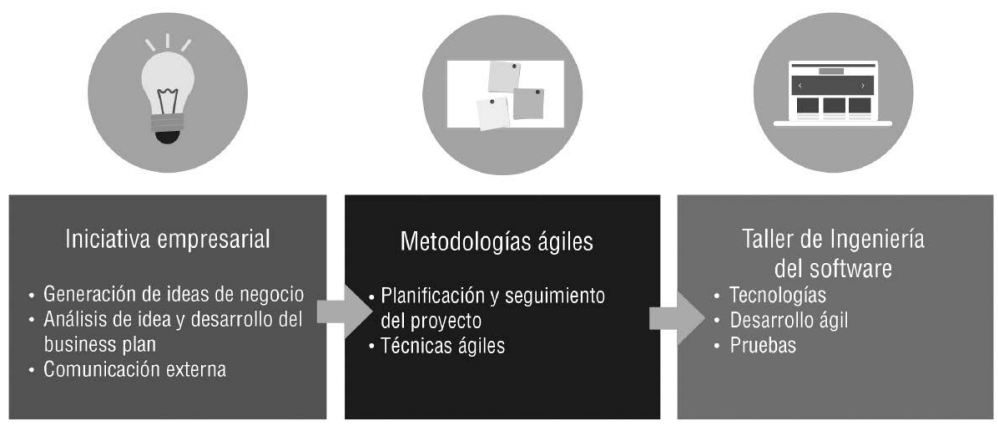

Fuente: elaboración propia 


\section{CONTEXTO DE LA EXPERIENCIA}

Para que el lector tenga una mejor imagen de la metodología utilizada, creemos necesario mostrar primero cada uno de los tres contextos o hélices que forman parte del modelo.

En primer lugar, el contexto docente hace referencia a la hélice universitaria en la que se ha implementado el proyecto. Las tres asignaturas que han participado pertenecen al grado en Ingeniería Informática de la Universitat Jaume I de Castellón de la Plana, dentro del itinerario de Ingeniería del Software (véase figura 2). Es una recomendación que los alumnos cursen como primera asignatura Iniciativa Empresarial, de carácter obligatorio, y que es impartida durante el primer semestre del último curso del grado. Esta asignatura tiene como competencia específica fomentar la «capacidad de poseer espíritu emprendedor y desarrollar la iniciativa empresarial en el ámbito de las $\mathrm{TIC}$ ».

Las otras dos asignaturas son Métodos Ágiles y Taller de Ingeniería del Software, ambas optativas en el itinerario de Ingeniería del Software, que se sitúan en cuarto curso, y se imparten en el segundo semestre. Se aconseja a los alumnos que se matriculen de ambas asignaturas durante el mismo curso académico. Una de las competencias de la asignatura Métodos Ágiles es «capacidad para identificar, evaluar y gestionar los riesgos potenciales asociados que puedan presentarse [durante el desarrollo del software]». Por su parte, la asignatura Taller de Ingeniería del Software trabaja las
Además, y siendo conscientes de la importancia de contar con la colaboración del alumnado de otras titulaciones directamente relacionadas con la creación de empresas, en la experiencia han participado alumnos del grado en Administración y Dirección de Empresas y también del máster interuniversitario en Marketing e Investigación de Mercados

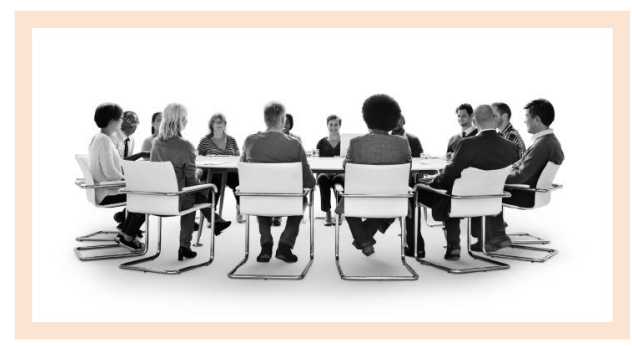

siguientes competencias: "trabajo en equipo, fomentando el respeto a la diversidad, la equidad y la igualdad de género» y "capacidad para diseñar soluciones apropiadas en uno o más dominios de aplicación, utilizando métodos de la ingeniería del software que integren aspectos éticos, sociales, legales y económicos».

Además, y siendo conscientes de la importancia de contar con la colaboración del alumnado de otras titulaciones directamente relacionadas con la creación de empresas, en la experiencia han participado alumnos del grado en Administración y Dirección de Empresas y también del máster interuniversitario en Marketing e Investigación de Mercados.

En segundo lugar, en el contexto de la hélice empresarial, han participado empresas de la provincia de Castellón, como Cuatroochenta, especializada en el desarrollo de aplicaciones para teléfonos inteligentes y tablets; Nayar Systems, empresa especializada en ingeniería de telecomunicaciones; y ADC Infraestructuras y Sistemas, empresa especializada en sistemas de telecontrol del ciclo integral del agua.

Por último, y en tercer lugar, en el contexto o hélice institucional han participado la propia universidad, a través del Centro de Educación y Nuevas Tecnologías, cuyo objetivo es promocionar la innovación y la mejora de los procesos de enseñanza-aprendizaje mediante las nuevas TIC; el Parque Científico, Tecnológico y Empresarial de la Universitat Jaume I (Espaitec), como nexo de unión entre el entorno académico y el tejido empresarial de la provincia de Castellón; y el Centro Europeo de Empresas e Innovación de Castellón (CEEl Castellón), organismo de apoyo a emprendedores y pymes con el objetivo de impulsar el desarrollo económico y social de la provincia de Castellón. 


\section{METODOLOGÍA DE TRABAJO}

La metodología que hemos aplicado para llevar a cabo la experiencia docente está basada en el ABP (Blumenfeld et al., 1991). Esta estrategia docente se centra en motivar a los alumnos, proponiéndoles una pregunta, inquietud, desafío o planteamiento que les oriente hacia la búsqueda de una solución. El ciclo del ABP cuenta con las siguientes etapas:

- Motivación.

- Propuesta de desafío.

- Adquisición de información y destrezas.

\section{La metodología que hemos aplicado para llevar a cabo la experiencia docente está basada en el ABP}

- Elaboración del producto mínimo viable.

- Evaluación y difusión de los resultados.

En nuestro caso, estas etapas generales se han concretado tal y como se presentan en la figura 3 .

\section{Figura 3. Metodología de trabajo}

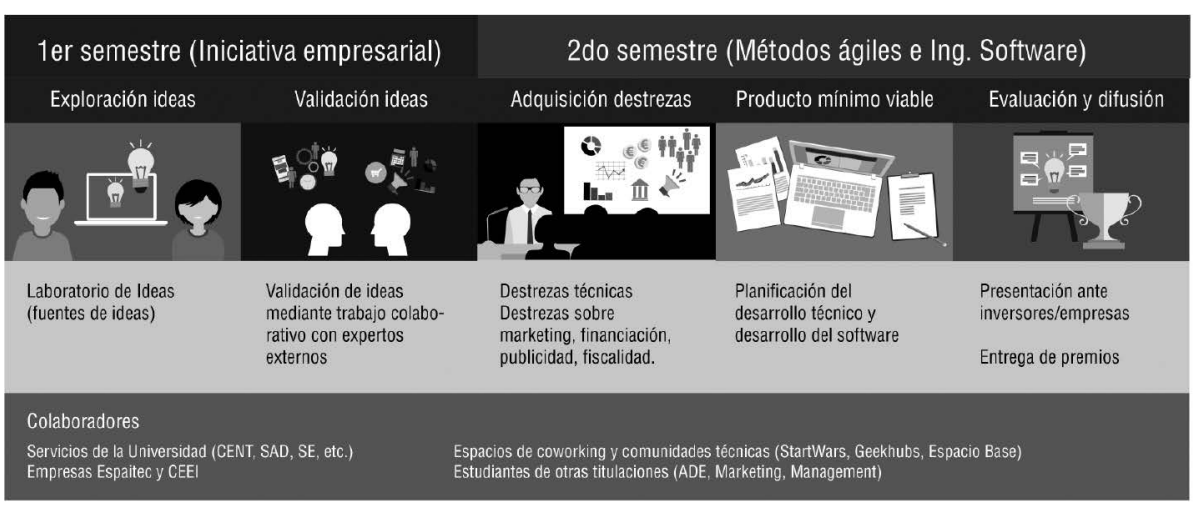

Fuente: elaboración propia.

\subsection{Motivación}

La motivación ha consistido en proponer a cada grupo de alumnos el desarrollo de un proyecto de base tecnológica propio, desde la gestación de la idea hasta la elaboración del producto mínimo viable. No es el profesor quien expone una idea de proyecto que el alumno debe hacer suya, sino el grupo de alumnos, quienes exploran las posibles ideas de proyectos y deciden cuál es el que quieren acometer. De este modo conseguimos que los alumnos se implique di- rectamente durante todo el proceso y estén más motivados, puesto que desde el principio sienten el proyecto como suyo y no que les ha sido impuesto por el profesorado.

Aun así hay alumnos que por distintos motivos se sienten más cómodos partiendo de una propuesta que no es propia. Esta posibilidad está contemplada en nuestra propuesta metodológica, y las alternativas que en este caso se le ofrecen al alumnado se detallan en el siguiente apartado. 


\subsection{La propuesta}

Dentro de la asignatura Iniciativa Empresarial (cuarto curso, primer semestre), el alumnado propone una idea de proyecto basándose en su propia experiencia ante necesidades concretas. Esta acción se corresponde con el primer cuadro de la figura 3. No todos los grupos de alumnos se sienten cómodos ante la propuesta de generar ideas. En estos casos se les ofrecen dos alternativas posibles.

La primera alternativa es que los alumnos de un grupo elijan un proyecto de entre un catálogo de propuestas elaborado por las empresas que participan en esta experiencia docente. Este catálogo está previamente validado por el profesorado, de modo que se adecua la dificultad y el alcance de cada una de las propuestas al tiempo disponible en las asignaturas, así como a los conocimientos tecnológicos del alumnado.

Existe una segunda alternativa para los alumnos más indecisos, en la que el profesorado de las asignaturas propone un proyecto tipo. Los proyectos propuestos están extraídos de la experiencia docente previa del profesorado, se encuentran perfectamente ajustados al tiempo disponible en las asignaturas, y los conocimientos técnicos necesarios para ejecutarlos forman parte de los contenidos teóricos de las mismas.

El siguiente paso en la elaboración de la propuesta es su validación. Esta actividad se corresponde con el segundo cuadro de la figura 3. Evidentemente, si el alumnado opta por alguna de las dos alternativas, la propuesta de proyecto se considera ya validada.

Durante la fase de validación se estudia la viabilidad comercial, económico-financiera y técnica de las propuestas. Para ello, y con el objetivo de que el alumnado se enfrente a una situación lo más realista posible, este presenta en una jornada sus ideas de negocio ante expertos externos provenientes de empresas de sectores TIC de Castellón, del Parque Científico de la universidad (Espaitec) y del CEEI. En esta jornada, y gracias a la colaboración de Espaitec, el alumnado tiene la oportunidad de presentar sus ideas para someterlas al juicio de expertos del sector y de estudiantes del grado de Administración y Dirección de Empresas. Tras cada una de las presentaciones se abre un turno de preguntas en las que afloran las fortalezas y debilidades de cada una de las propuestas, y se sugieren cambios 0 reorientaciones sobre la propuesta inicial realizada por el alumnado. Entre todos los asistentes al acto, y de manera representativa, se evalúan una serie de indicadores. Tras procesar todas las evaluaciones se selecciona el proyecto «mejor» valorado, y a sus integrantes se les otorga un premio consistente en disfrutar, durante seis meses, de un espacio de trabajo en Espaitec, así como en recibir apoyo por parte de su personal.

\subsection{Adquisición de información y destrezas}

Los contenidos teóricos necesarios para la gestión y el desarrollo de los proyectos son presentados a los estudiantes tanto en la asignatura Métodos Ágiles (cuarto curso, segundo semestre) como en la de Taller de Ingeniería del Software (cuarto curso, segundo semestre). Además, el alumnado participa en una serie de seminarios donde se profundiza en algún aspecto que se considera relevante para el desarrollo de los proyectos, o se estudian alternativas tecnológicas a las presentadas en las clases de teoría. Estos contenidos teóricos y seminarios pretenden desarrollar nuevas destrezas técnicas y de desarrollo de proyectos en los estudiantes. Estas acciones se corresponden con el tercer bloque de la figura 3.

Para desarrollar otro tipo de destrezas necesarias en la puesta en marcha de una iniciativa empresarial, hemos contado con la ayuda de actores pertenecientes a la hélice de la empresa. Estos actores se han presentado impartiendo charlas a los alumnos y se han puesto a su disposición para cualquier tipo de consulta que pudiese surgir durante su trabajo. Las empresas a las que pertenecen estos actores están todas radicadas en el Espaitec.

Las charlas a las que pudo asistir el alumnado fueron:

- Marketing. Colocación de nuevos productos en el mercado.

- Financiación. Detalles a tener en cuenta en la presentación ante inversores.

- Publicidad. Cómo conseguir descargas y gestionar campañas.

- Fiscalidad. Elementos fiscales que hay que tener en cuenta en la creación de empresas.

Tras cada una de las charlas se inicia un turno de preguntas en el que los alumnos muestran su interés en aspectos particulares de cada uno de los temas presentados. 


\subsection{Elaboración del producto mínimo viable}

Aunque la elaboración del producto mínimo viable es importante, en el contexto docente de este proyecto es igualmente fundamental todo el proceso de desarrollo de la idea, desde su concepción, pasando por la gestión y el desarrollo, hasta acabar con un producto con funcionalidad mínima, pero suficiente. Por ello, los alumnos son conscientes de que su objetivo no es el producto mínimo viable en particular, sino adquirir las destrezas que les conduzcan, con éxito, a ese producto. Esas destrezas les servirán en un futuro para abordar la puesta en marcha de nuevas ideas. Esta acción se corresponde con el cuarto bloque de la figura 3.

El desarrollo del proyecto se lleva a cabo utilizando metodologías de desarrollo ágiles y, en particular, Scrum Manager (Schwaber, 2004). Esta metodología de desarrollo descansa sobre cuatro pilares base propuestos en el Manifiesto Ágil (Agile Manifesto, 2016):

- Primar los individuos y sus interacciones frente a los procesos y las herramientas.

- Dar valor al software que funciona por encima de la documentación.

- Centrarse en la colaboración con el cliente frente a la negociación de contratos.

- Avanzar respondiendo al cambio antes que seguir un plan preestablecido.

En esta metodología de desarrollo, los requisitos del producto son especificados como historias de usuario. En cada historia de usuario se especifica una nueva funcionalidad que añade nuevo valor desde el punto de vista del usuario final. Al conjunto de todas las historias de usuario se le denomina «pila del producto». Esta pila del producto no es algo estático, inamovible, sino algo dinámico que puede y debe ir cambiando a lo largo del desarrollo del producto.

El desarrollo avanza por iteraciones, llamadas «sprints». Al inicio de cada iteración el cliente prioriza y selecciona un conjunto de historias de usuario de entre todo el conjunto disponible. El objetivo es seleccionar aquellas que más valor aportan al producto en el momento actual de su desarrollo. Cada iteración tiene un tiempo fijo, típicamente entre dos y cuatro semanas. El tiempo estimado de desarrollo de

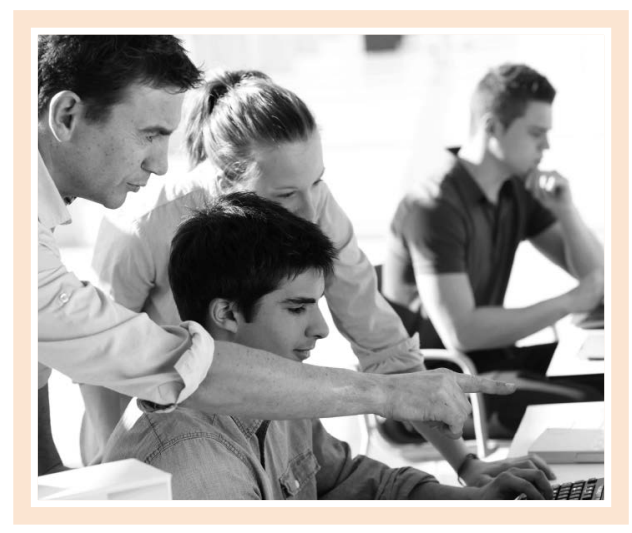

las historias seleccionado no debe superar el tiempo de la iteración. Al final de cada iteración hay una revisión del estado del producto por parte del cliente, y este decide si las historias de usuario se han cubierto satisfactoriamente o no. Un rol importante dentro de esta metodología de desarrollo es el Scrum Manager, quien juega el papel de facilitador, y su objetivo es resolver los problemas o interferencias que pueden aparecer en el desarrollo del proyecto. Este rol está compartido entre el profesor y un estudiante de cada grupo de forma rotatoria, de modo que todos los estudiantes desempeñan este rol al menos una vez durante el desarrollo del proyecto.

En nuestro caso particular, el papel del cliente, también llamado «propietario del producto», es desempeñado por el profesor, quien en este punto conoce bien cada uno de los proyectos, ha asistido a las sesiones de validación por parte de los usuarios y ha modulado el alcance del proyecto para que pueda ser desarrollado en el tiempo disponible y con los conocimientos adquiridos por el alumnado. La duración de cada iteración es de dos semanas, y hay cuatro iteraciones en total, resultando una duración total del proyecto de ocho semanas. Al inicio de cada iteración, el profesor acuerda con los alumnos de cada grupo qué historias de usuario entran en la nueva iteración. Al final de cada iteración, los alumnos presentan el estado del producto y el profesor valida si se han cubierto las historias de usuario planificadas. En la sesión de revisión se revisa la pila del producto y se eligen las historias de usuario que formarán parte de la nueva iteración. 
Al final de la última iteración los alumnos tienen construido un proyecto con toda la funcionalidad incluida en las historias de usuario del sprint actual y todos los anteriores. Dicho de otro modo, al final de cada sprint los alumnos disponen de un proyecto plenamente funcional, sin ser la versión final. Esto es de gran valor, ya que si el cliente, por algún motivo, decide detener el desarrollo del proyecto, siempre contará con un desarrollo que cumple parte de sus expectativas y no tendrá que esperar al final del periodo de desarrollo para tener una versión funcional del proyecto.

\subsection{Evaluación y difusión de los resul- tados}

En cada una de las tres asignaturas que forman parte de este proyecto, se utiliza un método de evaluación distinto, lo que creemos interesante, ya que el alumnado no acaba «especializándose» en superar un determinado tipo de prueba de evaluación, sino que tiene que someterse a la «disciplina» particular de cada tipo de evaluación. Esta acción se corresponde con el quinto bloque de la figura 3.

En la asignatura Iniciativa Empresarial los alumnos realizan un examen escrito, con un peso del $40 \%$ sobre la nota final. El restante $60 \%$ de la nota lo forma la evaluación de la resolución de casos y actividades prácticas.

En la asignatura Métodos Ágiles la evaluación se lleva a cabo con un contrato de aprendizaje, lo que supone el $100 \%$ de la nota final. En dicho contrato se especifican las condiciones para considerar que la asignatura está superada.

En la asignatura Taller de Ingeniería del Software se evalúa a partir del código fuente del proyecto entregado por los alumnos, con un peso del $85 \%$ sobre la nota final, y de una presentación, donde se evalúa la competencia del alumno en comunicación oral y escrita en inglés, con un peso del $15 \%$ sobre la nota final.

Tras la evaluación docente, para evitar posibles interferencias en la evaluación del alumnado, los alumnos hacen una presentación de su idea y materialización en el producto mínimo viable ante un grupo de posibles inversores. El objetivo de esta presentación es despertar el interés de posibles inversores sobre los proyectos del alumnado. Esta presentación es total-
En cada una de las tres asignaturas (...) de este proyecto, se utiliza un método de evaluación distinto, lo que creemos interesante, ya que el alumnado no acaba «especializándose» en superar un determinado tipo de prueba de evaluación, sino que tiene que someterse a la «disciplina» particular de cada tipo de evaluación

mente voluntaria, y solo los grupos de alumnos interesados en seguir adelante con sus ideas de proyecto la realizan. Uno de los posibles inversores, como premio independiente al interés que despierten las propuestas de proyecto, da un premio, a criterio propio, al mejor proyecto de los presentados. El premio consiste en la cesión gratuita de un espacio de co-working durante un periodo de entre cuatro y seis meses.

Finalmente, se pretende que los alumnos que han pasado por la experiencia durante un curso hagan de embajadores del proyecto ante sus compañeros del siguiente curso, contando su experiencia y valorando los aportes positivos que han obtenido de ella.

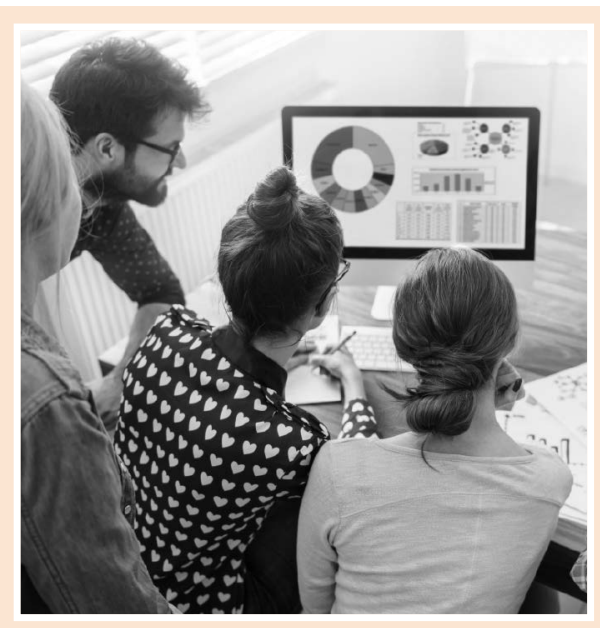




\section{RESULTADOS OBTENIDOS}

En este apartado se presenta un resumen de los principales resultados tangibles obtenidos en la experiencia docente llevada a cabo, puesto que los intangibles son numerosos, como se desprende de la valoración que el alumnado hace de la experiencia, y que se presenta en el apartado 6.

\subsection{Proyectos surgidos}

De la experiencia docente llevada a cabo entre las tres asignaturas surgieron un total de ocho proyectos en la asignatura de Iniciativa Empresarial, los cuales fueron evaluados por el profesorado con la finalidad de validarlos a nivel de plan de negocio. Además de esos ocho proyectos, los cinco mejores fueron validados por agentes externos, como se ha explicado en el apartado 4, en una fase adicional de validación en la que se analizó la viabilidad comercial, económico-financiera y técnica de las propuestas.

\section{Tras la evaluación docente, (...), los alumnos hacen una presentación de su idea y materialización en el producto mínimo viable ante un grupo de posibles inversores. El objetivo de esta presentación es despertar el interés de posibles inversores sobre los proyectos del alumnado}

Teniendo en cuenta que la asignatura Iniciativa Empresarial es obligatoria, mientras que las otras dos son optativas en el itinerario de Ingeniería del Software, el número final de proyectos que completaron la metodología fue de seis.

En el cuadro 1 se muestra el listado de los proyectos realizados por el alumnado de las tres asignaturas dentro de esta experiencia docente durante el curso académico 2015/2016.

\section{Cuadro 1. Proyectos desarrollados por el alumnado durante el curso 2015/2016}

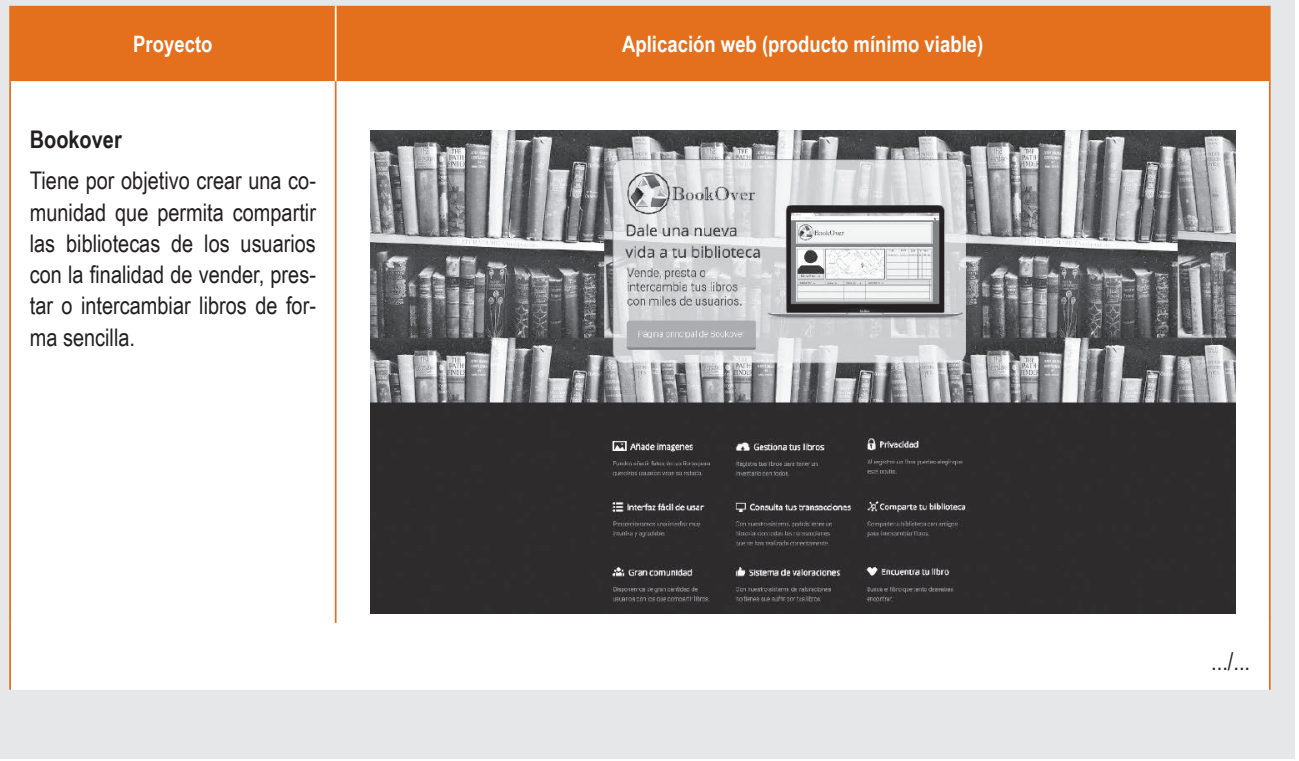


¿Cómo potenciar el emprendimiento y la innovación mediante el desarrollo / M. Segarra, R. Grangel, Ó. Belmonte y S. Aguado de proyectos de base tecnológica en el contexto docente universitario?

\section{Cuadro 1. Proyectos desarrollados por el alumnado durante el curso 2015/2016 (cont.)}

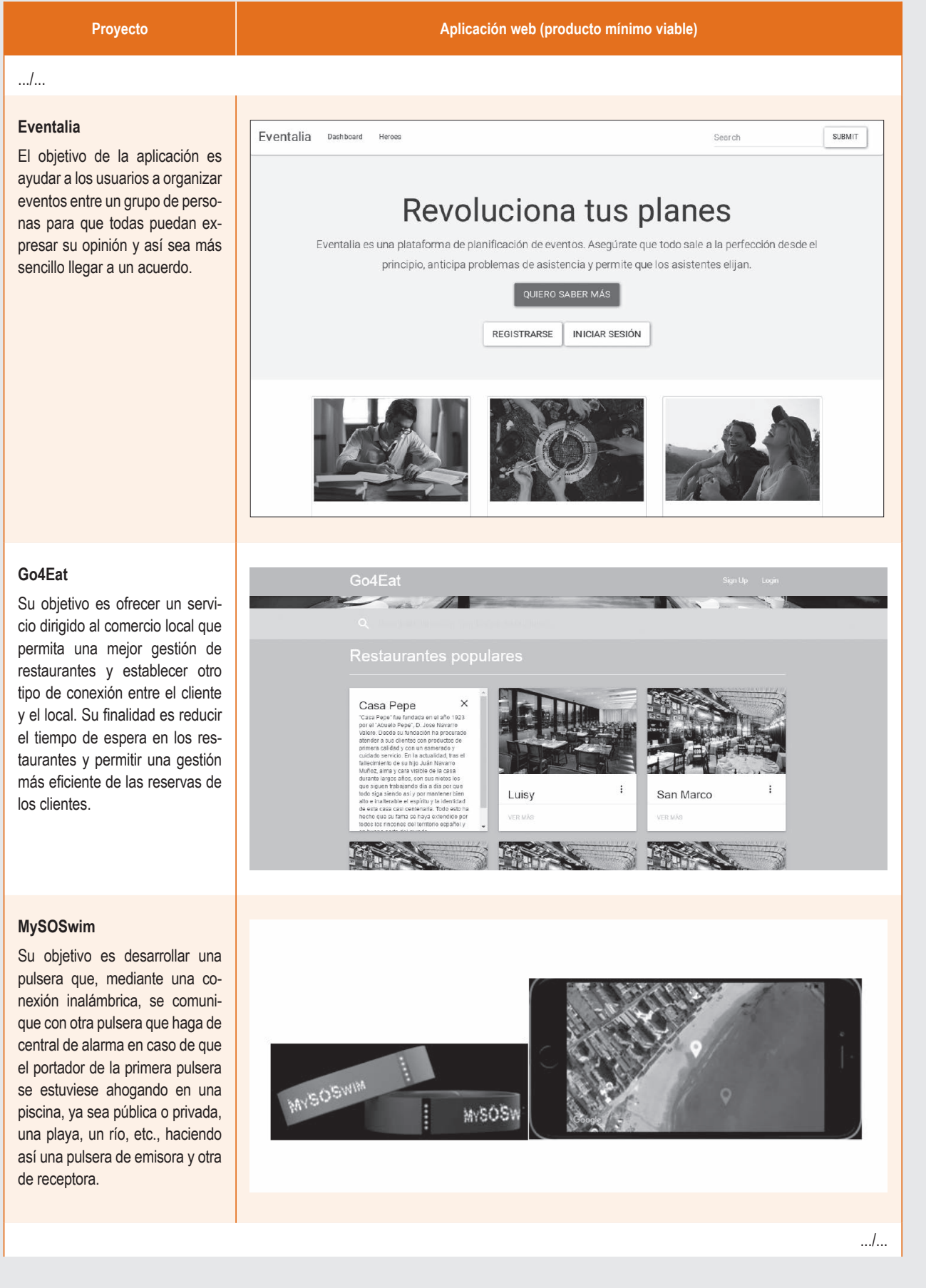




\section{Cuadro 1. Proyectos desarrollados por el alumnado durante el curso 2015/2016 (cont.)}

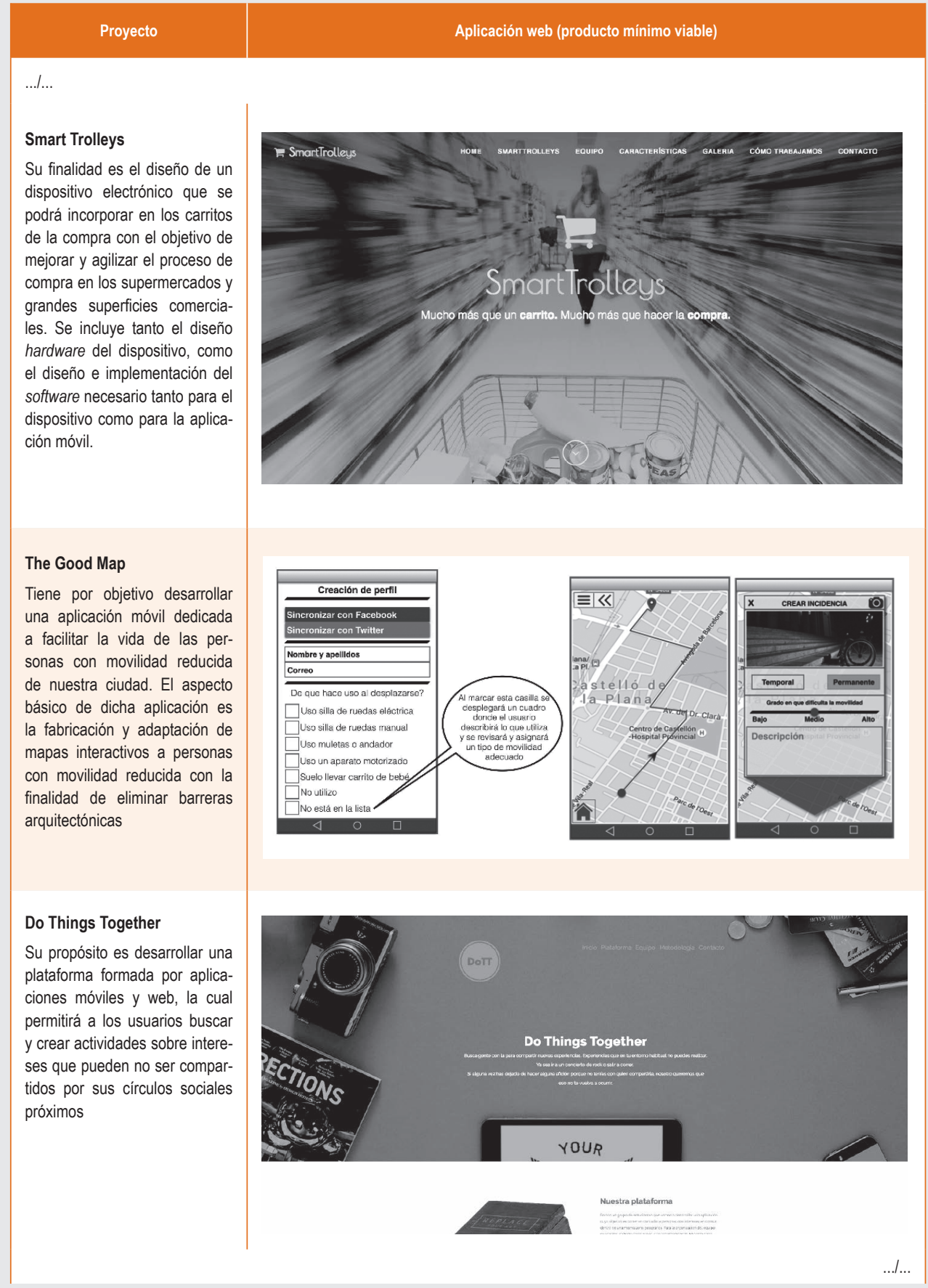




\section{Cuadro 1. Proyectos desarrollados por el alumnado durante el curso 2015/2016 (cont.)}

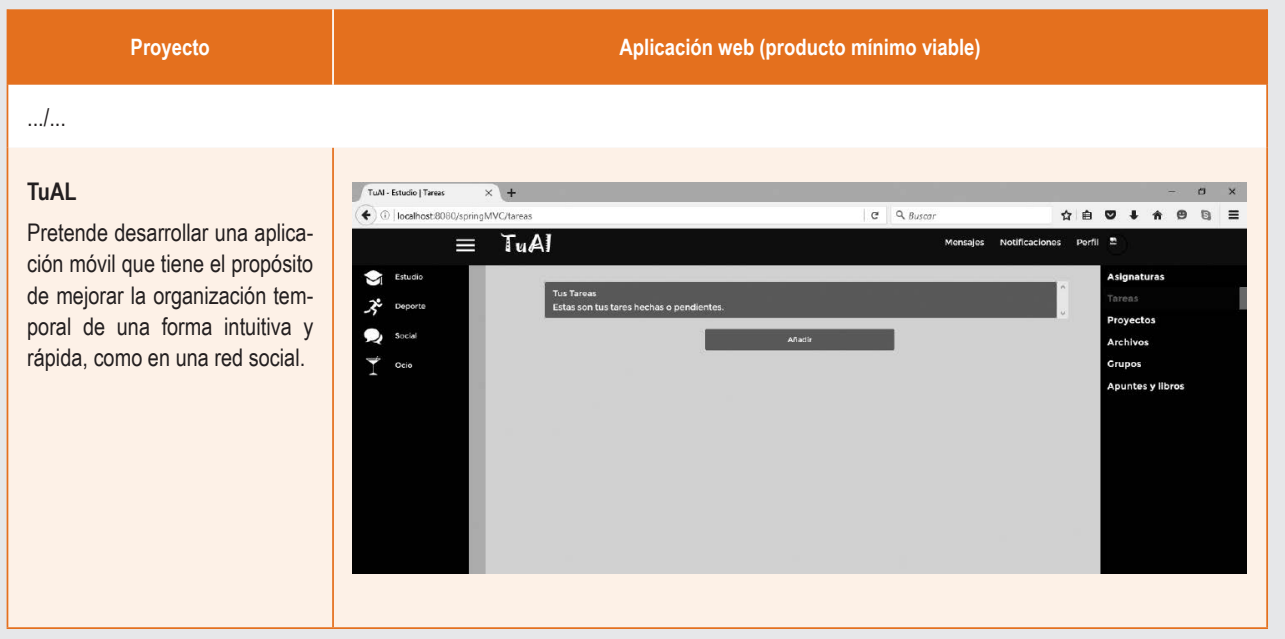

Fuente: elaboración propia.

\subsection{Colaboraciones realizadas}

Además de las colaboraciones expuestas en el apartado 3 , se llevaron a cabo otras actividades cooperativas entre distintos actores pertenecientes a cada una de las hélices, tal y como se detalla a continuación:

- Hélice Universidad. El alumnado del máster interuniversitario en Marketing e Investigación de Mercados participó en una presentación de los proyectos de los alumnos del grado en Ingeniería Informática. Al finalizar cada una de las presentaciones se estableció un turno de preguntas. Una vez finalizadas todas las presentaciones, los alumnos del máster y del grado tuvieron la oportunidad de relacionarse entre ellos, realizar más preguntas, dar opiniones y hacer consultas.

Los proyectos de los alumnos del grado en Informática fueron presentados a los del grado de Comunicación Audiovisual de la Universitat Jaume I. El objetivo era que estos últimos desarrollaran un vídeo promocional con la narración de cada uno de los proyectos: presentación de los integrantes de cada grupo, cómo surgió la idea, los beneficios que la solución aporta y cómo funciona.
- Hélice Empresarial. La empresa Nayar Systems I+D+i se implicó, tras la jornada en la que los grupos elegidos presentaron sus ideas de negocio ante expertos externos provenientes de empresas de sectores TIC de Castellón, del Parque Científico de la universidad (Espaitec) y del CEEl, en dar soporte técnico a uno de los proyectos participantes.

La empresa Start Wars realizó una presentación de su modelo de puesta en marcha de start-ups basado en el modelo de 24 pasos de Bill Aulet (Aulet, 2015).

- Hélice Institucional. El Departamento de Lenguajes y Sistemas Informáticos de la Universitat Jaume I, sensible ante el valor que supone para el alumnado, y el esfuerzo por parte del profesorado, de la puesta en marcha de este proyecto de mejora educativa, financia la entrega de premios a los mejores proyectos presentados por los alumnos. 


\section{VALORACIÓN DE LA EXPERIENCIA}

La elaboración del cuestionario que se ha pasado al alumnado para analizar cómo ha cambiado su percepción sobre el emprendimiento se ha basado, en primer lugar, en el trabajo previo presentado en el cuestionario de Peterman y Kennedy (2003) sobre la percepción de la viabilidad y la conveniencia percibida por los emprendedores, $y$, en segundo lugar, en las competencias analizadas en la literatura que serían deseables en un emprendedor.

De esta manera, el cuestionario se ha organizado en dos grandes apartados:

- Primera parte. Contiene preguntas sobre la viabilidad y la conveniencia que el alumnado percibe del emprendimiento tras llevar a cabo la experiencia docente. Las preguntas en esta parte del cuestionario van encaminadas a averiguar en qué grado la experiencia docente ha modificado su actitud hacia el emprendimiento. Para ello, la mayor parte de preguntas se contestan según la escala Likert, de 1 a 5 . También se han añadido algunas preguntas de respuesta cerrada para valorar la experiencia, por ejemplo, como positiva o negativa, $y$, finalmente, se han añadido un conjunto de preguntas sobre su experiencia empresarial para poder realizar un análisis mejor.

- Segunda parte. Contiene preguntas sobre las capacidades que debería tener un emprendedor a nivel personal y social con la finalidad de poder conocer en qué grado la experiencia docente ha enriquecido o no las mismas. Esta parte también se valora según la escala Likert, de 1 a 5.

Tras el análisis de las respuestas obtenidas al cuestionario pasado al alumnado, cuyas preguntas se detallan en el anexo, la valoración es que la experiencia docente ha resultado positiva para la totalidad del alumnado. Además, por los comentarios particulares, los alumnos valoran el esfuerzo del profesorado por acercarles al mundo empresarial y por coordinar las tres asignaturas mencionadas en la consecución de un proyecto único. Como único punto débil señalan la carga de trabajo que supone llevar a cabo un proyecto de esta envergadura en la recta final del grado, cuando están inmersos en el desarrollo, al mismo tiempo, del trabajo final de

\section{(...) los alumnos valoran el esfuerzo del profesorado por acercarles al mundo empresarial y por coordinar las tres asignaturas mencionadas en la consecución de un proyecto único}

grado; si bien, desde el punto de vista del profesorado, estos comentarios reflejan el nivel de implicación y la motivación del alumnado con el proyecto, puesto que, en ocasiones, algunos trabajos exceden ampliamente los mínimos exigidos en las asignaturas, puesto que los alumnos se ilusionan con el proyecto y le dedican finalmente más horas de las que sería necesario para obtener un mínimo producto viable.

Analizando el gupo de alumnos, desde el punto de vista de su experiencia personal en el contexto del emprendimiento, cabe señalar que no se trata de un grupo de alumnos especialmente vinculado a la figura del emprendedor, aunque sí con cierto conocimiento o contacto con este dominio. Por ejemplo, llama la atención que, a pesar de ser alumnos que todavía no han finalizado sus estudios, puesto que están en cuarto curso, un $25 \%$ de ellos declaran haber trabajado en una start-up, y un $40 \%$, haber comenzado un proyecto propio, lo cual, si bien es mejorable, demuestra un cierto carácter emprendedor o innovador para alumnos que aún no han finalizado sus estudios. Todo ello teniendo en cuenta que, aunque en su mayoría el alumnado ( $85 \%$ ) conoce casos de amigos que han comenzado un negocio, este porcentaje baja al $60 \%$ cuando el caso se restringe a su entorno familiar más cercano.

En lo referente a la variación en la percepción sobre el emprendimiento que ha tenido el alumnado, se puede observar cómo la mayor parte de las valoraciones ha obtenido una respuesta superior a 3, por lo que, en general, sí que se puede percibir esa variación en sentido positivo.

Analizando los resultados, al final del curso, el $80 \%$ de los estudiantes ve más posible el hecho de crear una empresa que al inicio del mismo curso. 
Con respecto a la viabilidad percibida, un $45 \%$ considera que han mejorado bastante los recursos de los que dispone para afrontar el proyecto de crear una nueva empresa, mientras que un $25 \%$ considera que han mejorado notablemente, y solo un $5 \%$ que no los han mejorado de forma apreciable. De igual forma, la confianza en uno mismo a la hora de crear un negocio ha experimentado una mejora notable según el $55 \%$ de los encuestados (véase figura 4$)^{5}$.

Finalmente, en esta categoría cabe destacar la respuesta a la pregunta sobre la disminución en la percepción de la carga de trabajo necesaria para poner en marcha un proyecto (véase figura 5). En este caso se puede observar cómo no hay una clara mejora en la variación percibida, al contrario de lo que se observaba en el caso de la mejoría en los recursos propios a la hora de poner en marcha un proyecto (véase figura 4). Quizás se pueda deber a que el trabajo en equipo a nivel docente siempre es sobrellevado de manera desigual por parte del equipo y de ahí esa variación en las respuestas, donde hay alumnos que ven que sí ha disminuido el trabajo que ellos pensaban que conllevaría poner en marcha el proyecto $y$, para otros, en cambio, esta percepción ha aumentado, influenciados por la marcha del equipo a nivel docente.

Por último, hay que comentar también que en esta categoria hay una pregunta que sobresale en la tendencia positiva de la variación de la percepción del alumnado hacia el emprendimiento. Es el caso en el que se pregunta al alumnado sobre el estrés que le supone la idea de poner en marcha su proyecto (véase figura 6).

En este caso, el porcentaje de alumnos que se siente menos estresado es muy bajo, en torno a un $5-20 \%$, y, en cambio, hasta un $35 \%$ y un $15 \%$ afirman sentirse más estresados o mucho más estresados, respectivamente. Estos porcentajes se pueden explicar por el hecho de que, a pesar del valor que le damos a la experiencia docente, no deja de ser solo una experiencia. Con ella introducimos al alumnado en un mundo nuevo, como es el emprendimiento, y le damos las bases para que empiece a emprender e innovar, pero, evidentemente, es solo el comienzo. Por tanto, el alumnado se encontraría en esa fase en la cual está muy motivado e ilusionado por emprender (hasta un $80 \%$ veía más posibilidades de emprender un negocio). Pero, al mismo

\footnotetext{
5 En los gráficos de las figuras 4 a 6, el eje de abscisas se corresponde con la escala Likert, y el de ordenadas, con el número de respuestas y su porcentaje.
}

Figura 4. Cuestionario universitario. Viabilidad percibida. Pregunta sobre los recursos

Con la formación adquirida, ¿crees que han mejorado tus recursos para poner en marcha tu proyecto?

(20 respostes)

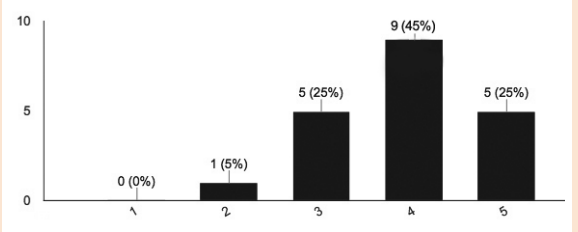

Fuente: elaboración propia.

Figura 5. Cuestionario universitario. Viabilidad percibida. Pregunta sobre la carga de trabajo

Con lo que has aprendido, ¿crees que ha disminuido tu percepción de la carga de trabajo necesaria para poner en marcha tu proyecto?

(20 respostes)

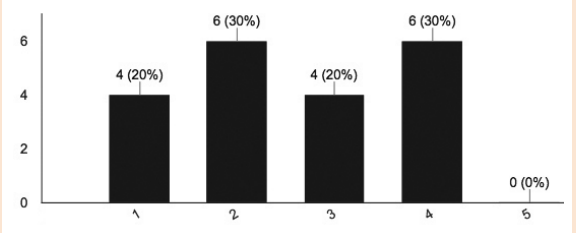

Fuente: elaboración propia.

Figura 6. Cuestionario universitario. Conveniencia percibida. Pregunta sobre el estrés que genera la idea de poner en marcha el proyecto

¿Te resulta más o menos estresante ahora la idea de poner en marcha tu proyecto?

(20 respostes)

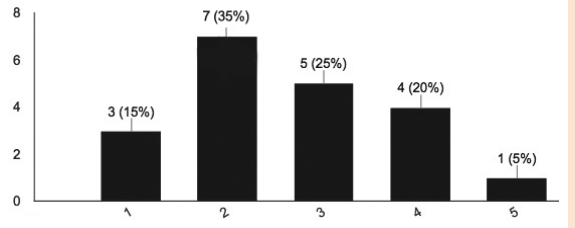

Fuente: elaboración propia. 


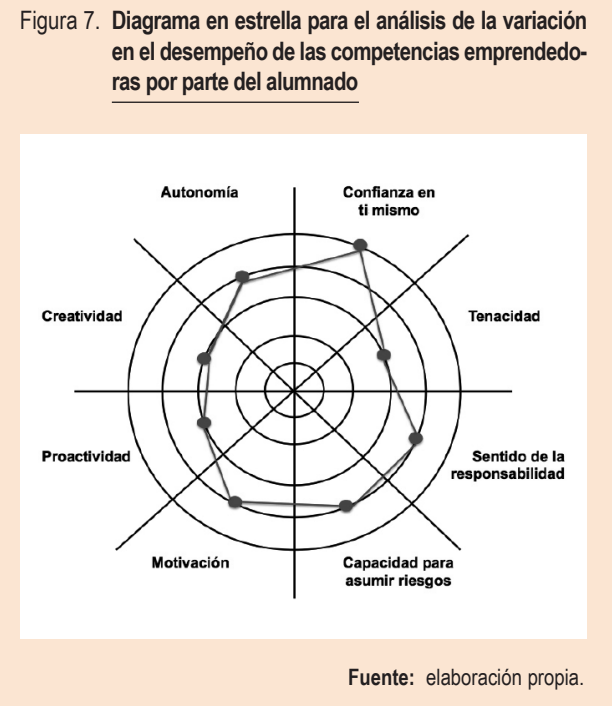

tiempo, es consciente de las dificultades que ello conlleva, porque el emprendimiento ya no es una idea abstracta, sino que lo ha puesto en práctica.

Para terminar con el análisis del cuestionario, en la segunda parte del mismo se ha preguntado en qué medida el alumnado percibía que sus competencias emprendedoras habian variado tras la experiencia docente. Para llevar a cabo el análisis de esta segunda parte del cuestionario se ha usado un diagrama en estrella (véase figura 7), en el cual se recogen las valoraciones para las distintas competencias analizadas (se presenta el análisis para las competencias personales), siendo el centro de la diana la valoración inferior (1) y los extremos distantes la valoración máxima (5).

\section{El objetivo final ha sido udespertar» la iniciativa y el emprendimiento en los alumnos, acompañándolos en todo el proceso desde el mundo docente y recibiendo el apoyo de actores de la Hélice Empresarial e Institucional}

El diagrama de la figura 7 nos da una imagen representativa de la medida en que han mejorado las competencias emprendedoras en el alumnado que ha participado en la experiencia docente a nivel personal. Se puede observar cómo el grado de adquisición de la competencia se encuentra en valores intermedios, puesto que es la primera vez que esta se trabaja en el grado. Sin embargo, se puede observar cómo hay capacidades que se refuerzan muy positivamente, como el caso de la motivación.

Finalmente, sobre la valoración recogida cabe señalar que el alumnado ha respondido por encima del $75 \%$, si bien las limitaciones del estudio se deben a las de la propia muestra. Como posibles mejoras se piensa replicar la experiencia en los otros itinerarios del grado, así como la posibilidad de aplicarlo a otros estudios de la universidad. En la aplicación del cuestionario, además, se ha detectado la necesidad de matizar las preguntas y añadir nuevas cuestiones en la aplicación de la experiencia para el próximo curso, de forma que se pueda recabar una opinión más matizada del alumnado.

\section{CONCLUSIONES}

El resultado y las conclusiones de la experiencia docente que se expone en este artículo se pueden explicar desde los tres ámbitos de la Triple Hélice:

- Universitaria. Por una parte, los alumnos adquieren unas competencias transversales para emprender en su propia empresa o dentro de empresas existentes. La interacción con otros grados y, por lo tanto, con otros perfiles de alumno representa una ventaja ante la situación actual, donde los estudiantes no tienen interacción más allá de sus competencias troncales. Conocer otros perfiles en el inicio de una fase empresarial es crítico para una buena ejecución de un proyecto empresarial. Esta vertiente enlaza con la propuesta de la Comisión Europea, en la cual se propugna que la enseñanza de las competencias emprendedoras debe tener un enfoque interdisciplinar.

- Empresarial. Las competencias de estos alumnos son ampliamente valoradas dentro del tejido empresarial, pues son alumnos preparados para la toma de decisiones. Es importante destacar de nuevo que adquirir competencias empresariales no supo- 
ne únicamente iniciar una empresa, puede suponer la creación de un nuevo departamento o línea de negocio. Por lo tanto, el objetivo es que el alumno tenga la capacidad de emprender dentro de la misma empresa, como un actor que es capaz de mejorar los procesos e innovar.

- Institucional. Alumnos preparados con competencias emprendedoras favorecen la creación de nuevas empresas y, por lo tanto, la aceleración en la creación de empleo. Al mismo tiempo, se espera que la valoración positiva de la experiencia recibida los anime a participar en el proyecto, formando parte de la hélice empresarial, y, con ello, que las instituciones y la sociedad reciban un retorno del esfuerzo llevado a cabo en la hélice universitaria.

Hasta donde alcanza nuestro conocimiento en la materia, es la primera vez que la base teórica del modelo de la Triple Hélice se aplica teniendo como motor a la hélice universitaria. El objetivo final ha sido «despertar» la iniciativa y el emprendimiento en los alumnos, acompañándolos en todo el proceso desde el mundo docente y recibiendo el apoyo de actores de la Hélice Empresarial e Institucional. Creemos haber conseguido el objetivo a la luz de los resultados obtenidos a través de las encuestas realizadas a los alumnos. Los alumnos nos han comunicado que se sienten más motivados a emprender y que su nivel de estrés ante

\section{BIBLIOGRAFÍA}

Agile Manifesto [2016]: http://agilemanifesto.org/ [Consultado: 3 de mayo de 2016].

Arenius, P. y Minniti, M. [2005]: «Perceptual variables and nascent entrepreneurship», Small Business Economics, 24 (3), págs. 233-247.

Aulet, B. [2015]: La disciplina de emprender, Madrid: LID.

Batista Canino, R. M.; Fernández-Laviada, A.; Medina Brito, M. ${ }^{a}$ del P.; Esteban Lloret, N. N.; Rueda Sampedro, I. y Sánchez Ruiz, L. [2015]: «Educación en emprendimiento», en I. P. Legazkue, M. Guerrero y J. L. González-Pernía (eds.), Global entrepreneurship monitor: Informe GEM España 2014, 18, Santander: Universidad de Cantabria, págs. 125-145.

\section{Los alumnos nos han comunicado que se sienten más motivados a emprender y que su nivel de estrés ante dicha posibilidad se ha reducido gracias a que han contado con la participación de otros actores tradicionalmente alejados del ámbito docente (especialistas en finanzas, marketing y publicidad, inversores, etc.)}

dicha posibilidad se ha reducido gracias a que han contado con la participación de otros actores tradicionalmente alejados del ámbito docente (especialistas en finanzas, marketing y publicidad, inversores, etc.).

Creemos, además, que esta metodología basada en la Triple Hélice se puede replicar, con los ajustes necesarios, a otras disciplinas académicas, siempre que se cuente, evidentemente, con el apoyo de actores provenientes de la empresa/industria y las instituciones.

Blumenfeld, P. C.; Soloway, E.; Marx, R. W.; Krajcik, J. S.; Guzdial, M. y Palincsar, A. [1991]: «Motivating projectbased learning: sustaining the doing, supporting the learning», Educational Psychologist, 26 (3-4), págs. 369-398.

Bologna Process [2016]: http://www.ehea.info [Consultado: 3 de mayo de 2016].

Castillo, H. G. C. [2010]: «El modelo de la triple hélice como un medio para la vinculación entre la universidad y empresa», Revista Nacional de Administración, 1 (1), págs. 85-94.

Clark, B. R. [1998]: Creating entrepreneurial universities: organizational pathways of transformation, Oxford: Pergamon. 
Comisión Europea [2006]: Recomendaciones del Parlamento Europeo y del Consejo de 18 de diciembre de 2006 sobre las competencias clave para el aprendizaje permanente (Diario Oficial de la Unión Europea, 30-12-2006).

[2008]: La iniciativa emprendedora en la enseñanza superior, especialmente en estudios no empresariales, Dirección General de Empresa e Industria.

Etzkowitz, H. y Leydesdorff, L. [2000]: «The dynamics of innovation: from National Systems and "Mode 2" to a Triple Helix of university-industry-government relations», Research Policy, 29 (2), págs. 109-123.

Etzkowitz, H. y Ranga, M. [October 2010]: «A Triple Helix System for knowledge-based regional development: from "Spheres" to "Spaces"», VIII Triple Helix Conference, Madrid.

Etzkowitz, H.; Webster, A.; Gebhardt, C. y Terra, B. C. R. [2000]: «The future of the university and the university of the future: evolution of ivory tower to entrepreneurial paradigm», Research Policy, 29 (2), págs. 313-330.

Fundación Príncipe de Girona [2011]: Libro blanco de la iniciativa emprendedora en España, Resumen Ejecutivo, FPdGi.

Krueger, N. y Casrud, A. L. [1993]: «Entrepreneurial intentions: applying the theory of planned behavior», Entrepreneurship and Regional Development, 5, págs. 315-330.

Leydesdorff, L.; Dolfsma, W. y Panne, G. van der [2006]: «Measuring the knowledge base of an economy in terms of triple-helix relations among "tech- nology, organization, and territory», Research Policy, 35 (2), págs. 181-199.

McClelland, D.; Atkinson, J.; Clark, R. y lowell, E. [1953]: The achievement motive, New York: Appleton-Century-Crofts.

Miró, J. y Jaume, A. [2010]: «Repositorio de actividades para enseñar competencias transversales», REDU. Revista de Docencia Universitaria, 8 (1), págs. 101-110.

Peterman, N. E. y Kennedy, J. [2003]: «Enterprise education: influencing students' perceptions of entrepreneurship», Entrepreneurship Theory and Practice, 28 (2), págs. 129-144.

Pittaway, L. y Cope, J. [2007]: «Entrepreneurship education a systematic review of the evidence», International Small Business Journal, 25 (5), págs. 479510.

Schwaber, K. [2004]: Agile project management with Scrum, Redmond (Washington): Microsoft Press.

Scrum Manager [2016]: https://www.scrumalliance.org/ community/articles/2014/august/agilegamification [Consultado: 3 de mayo de 2016].

Shane, S. A. [2004]: Academic entrepreneurship: university spinoffs and wealth creation, United Kingdom: Edward Elgar Publishing.

Viale, R. y Etzkowitz, H. [2005]: «Third academic revolution: polyvalent knowledge; the DNA of the triple helix», Fifth Triple Helix Conference, págs. 18-21.

Wagenaar, R. (ed.) [2003]: Tuning educational structures in Europe. Final report. Phase one, Bilbao: University of Deusto. 


\section{ANEXO}

\section{Cuestionario universitario}

\section{CUESTIONARIO UNIVERSITARIO SOBRE EL EMPRENDIMIENTO}

Primera parte. Percepción de los estudiantes sobre el emprendimiento tras la realización del proyecto realizado en las asignaturas de Iniciativa Empresarial, Métodos Ágiles y Taller de Ingeniería del Software (adaptado de Peterman y Kennedy, 2003)

\section{Intenciones}

1. ¿Te ves con más posibilidades ahora que al inicio del curso de crear una empresa o comenzar un negocio? Sí No

Viabilidad percibida

2. ¿Te parece ahora más asequible la puesta en marcha de una iniciativa propia?
(1) Nada asequible.
(5) Muy asequible.

3. ¿Qué certeza tienes ahora del éxito de tu proyecto en comparación con el momento en que surgió la idea al inicio del curso?
(1) Fracaso seguro.
(5) Éxito seguro.

4. Con lo que has aprendido, ¿crees que ha disminuido tu percepción de la carga de trabajo necesaria para poner en marcha tu proyecto?
(1) No ha disminuido nada.
(5) Ha disminuido mucho.

5. Con la formación adquirida, ¿crees que han mejorado tus recursos para poner en marcha tu proyecto?
(1) No ha mejorado nada.
(5) Ha mejorado mucho.

6. Con la formación adquirida, ¿crees que ha mejorado la confianza en ti mismo a la hora de poner en marcha tu proyecto?
(1) No ha mejorado nada.
(5) Ha mejorado mucho

\section{Conveniencia percibida}

7. Después de la experiencia vivida en las asignaturas, ¿en qué medida te gustaría poner en marcha tu proyecto?
(1) No me gustaría nada.
(5) Me gustaría mucho.

8. ¿Te resulta más o menos estresante ahora la idea de poner en marcha tu proyecto?
(1) Más estresante.
(5) Menos estresante.

9. ¿Ha crecido tu entusiasmo desde el momento en que planteaste la idea hasta el momento actual?
(1) No ha crecido nada.
(5) Ha crecido mucho. 


\section{CUESTIONARIO UNIVERSITARIO SOBRE EL EMPRENDIMIENTO}

$\ldots / .$.

Positividad de la experiencia

10. ¿La experiencia docente ha sido positiva o negativa?

Positiva

Negativa

\section{Experiencia empresarial}

11. ¿Tus padres 0 algún familiar ha iniciado alguna vez un negocio?

$$
\square \text { Sí } \quad \square \text { No }
$$

12. ¿Alguna persona que conoces ha empezado un negocio?

$$
\square \text { Sí }
$$

13. ¿Has trabajado para una start-up?

$$
\square \text { Sí } \quad \square \text { No }
$$

14. ¿Alguna vez has comenzado un proyecto propio?
$\square$ Sí
$\square$ No

Segunda parte. Por último, en relación a las capacidades que se le reconocen a un emprendedor, nos gustaría que valoraras [escala Likert: de 1 (poco) a 5 (mucho)] cómo han variado las siguientes capacidades tras realizar la experiencia docente.

\section{Personal}

\section{Creatividad}

16. Autonomía

17. Confianza en ti mismo

18. Tenacidad

19. Sentido de la responsabilidad

20. Capacidad para asumir riesgos

21. Motivación

22. Proactividad

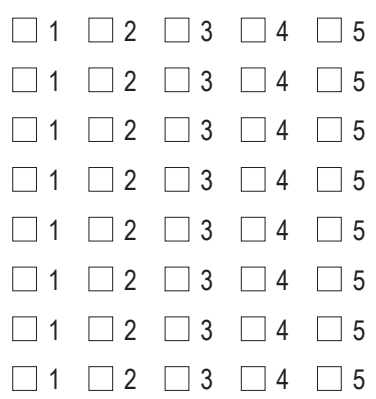

Social

23. Liderazgo

24. Espíritu de equipo

25. Solidaridad

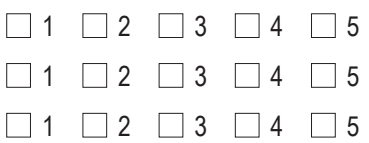

